\title{
Corrigendum: A submarine volcanic eruption leads to a novel microbial habitat
}

Roberto Danovaro, Miquel Canals, Michael Tangherlini, Antonio Dell'Anno, Cristina Gambi, Galderic Lastras, David Amblas, Anna Sanchez-Vidal, Jaime Frigola, Antoni M. Calafat, Rut Pedrosa-Pàmies, Jesus Rivera, Xavier Rayo and Cinzia Corinaldesi

Nature Ecology \& Evolution 1, 0144 (2017); published 24 April 2017; corrected 22 May 2017.

In the original version of this Article Rut Pedrosa-Pàmies's name was listed incorrectly. This has been updated in all versions of the Article. 